\title{
MAKING CROSS-INSTITUTIONAL COALITIONS WORK: A View into the Workings of a Successful Seven Institution Collaboration
}

\author{
Barbara Bogue, Rose Marra \\ The Pennsylvania State University, University of Missouri, Columbia
}

Cross institutional coalitions are encouraged by funders such as the National Science Foundation and offer many substantial advantages. They also offer significant challenges. With disparate institutions often operating at significant geographical distances and with differing levels of institutional support, successful coalitions take careful management and planning to succeed.

The development of the AWE Project coalition, an NSF funded (HRD 01 20642) project designed to develop effective assessment tools and models for WIE and similar programs (11, 12). AWE comprises seven very different institutions, programs in varying states of development, and a range of staffing and funding resources. AWE Partner Institutions are the University of Missouri (Marra), Penn State (Bogue), Georgia Tech (Mimi Philobos), the University of Arizona (Marie Reyes), the University of Louisville (Brenda Hart), the University of Texas - Austin (Tricia Berry) and Rensselaer Polytechnic Institute (Barbara Ruel). The three year project required that each institution and WIE director or research associate participate fully in developing and testing assessment instruments with large numbers of students, documentation and career development tools.

This paper will look at the rewards and challenges of coalitions in general and, using initial assessment of the AWE experience as a example, identify ways that PIs and grant subcontractors can be engaged successfully in a productive and mutually rewarding process; how full participation of collaborators can be realized; what organizational tools and processes help to achieve collaborator ownership of the overall project; and how to document process.

\section{Coalitions-Benefits and Drawbacks}

Coalitions became a familiar feature of engineering education in the late 80's when the NSF launched the Engineering Education Coalitions, an initiative that responded to the 1989 Belmont Conference on Imperatives in Undergraduate Engineering Education that identified the need to synthesize knowledge, push interdisciplinarity, emphasize practice and the participation of underrepresented groups and so on, presaging the ABET 2000 criteria. (5) Each coalition required the participation of a group of diverse engineering education institutions that would work together to re-design how engineering education was delivered, with an emphasis on developing a diverse student population. Six coalitions were funded. (The authors first collaborated themselves through the ECSEL Coalition.) An underlying idea was that coalitions would solve the problem of effective initiatives being developed at one institution, but never going any farther; the coalitions would have built in dissemination, as each institution in the coalition exported the ideas of the others.

"Proceedings of the 2005 American Society for Engineering Education and Annual Conference \& Exposition" Copyright, American Society for Engineering Education 
The coalition initiative had many successes and provided a model for such efforts. As noted on the NSF Engineering directorate home page, "These efforts integrate new knowledge across disciplines, accelerate technology development, and improve the capabilities and diversity of engineering graduates entering the technical workforce." (13) (add more - do literature review on coalition .. there must be an evaluation report too?)

While the concept of coalitions is well accepted, the actual practice remains challenging. A Mid Coalition Program Evaluation by SRI International lays out the pitfalls well, noting that "Most impacts had been intra-institutional, indeed, intra-disciplinary." (SRI, pg. 4) They went on to note that dissemination, one of the underlying objectives of the coalitions, remained "nominal" with most dissemination taking the form of information exchange in coalition or national conferences. Furthermore their survey of participating engineering deans indicated that there was little adoption of initiatives beyond the coalition partners and that many faculty were clinging to the "not invented here" syndrome. Finally, the faculty who were doing the innovating were understandably not ready to also do the follow up work of effective dissemination. SRI notes that "interaction between the innovators and the rest of the community is fleeting, documentation limited, and adaptability widely questioned." (5)

Additional drawbacks to coalitions are expense, the additional time that it takes collaborators to collaborate (e.g., away from primary job responsibilities); increased administration efforts; the need to deal with varying administration policies and styles at disparate institutions (10); and the time and effort needed to determine that everyone has the same understanding of the coalition goals and objectives and identify the skills and information needed to have all collaborators at the same operating and knowledge levels. (2)

A daunting list. But the benefits are also numerous and, in our experience, far outweigh the costs and challenges and can be detailed in three main categories devised by Hardy, Phillips and Lawrence (8) based on extensive, interdisciplinary reviews:

- Strategic (leveraging of resources and experience);

- Knowledge Sharing and Creation (exchange of existing and new knowledge, including tacit knowledge, plus the synergy gained from interaction among diverse individuals at diverse institutions);

- Political (increasing professional networking and visibility).

These categories provide a framework for the development of designing and assessing strategies in the AWE collaboration.

Effective inter-institutional collaborations also "can serve a change management role by being more entrepreneurial and less conservative than the institutions they represent". (9) Or, in a description of NSF Engineering Education, the principles of which can apply to such collaborations in general: "Coalition partners draw on their diverse strengths and mutual support to construct improved curricula and learning environments; to attract and retain a more demographically diverse student body, and to graduate a new generation of engineers who can more effectively solve the increasingly complex, rapidly changing societal problems." (7)

"Proceedings of the 2005 American Society for Engineering Education and Annual Conference \& Exposition" Copyright, American Society for Engineering Education 


\section{Methodology for Assessing AWE Project Collaboration}

Recognizing the need to be aware of our collaboration processes and to constantly tune them, we built in several methods to track the progress of the collaboration and its impact on grant outcomes and the participants from the beginning of the AWE project:

1. Annual electronic survey of participant experience in the project

2. Electronic feedback webforms for all products under development

3. Assessment results from annual meetings and regularly scheduled telephone conference calls

4. Individual phone calls to gain feedback on specific topics and on experience in grant in general

5. Ethnographic notes based on feedback to developed processes and implementation of processes

While the thrust of the assessment plan above was to measure the efficacy of the collaboration, the most valuable outcome, as so often happens, was to strengthen the commitment to the project and build an active community based on achievement of the project objectives. This speaks to an underlying precept of the overall AWE Project: that well planned assessment is integrated into an activity or larger program in a holistic way that provides the platform for a systems approach to program development. The regular and systematically sought director input meant that we were constantly asking "what's possible?" "What's missing?" and "how can we do this better?" The result was that the products developed are lean and based on what is possible for a busy director to achieve, highly usable and relevant.

The results presented here are from the annual electronic survey (\#1, above).

\section{How AWE Addressed Collaboration Challenges}

Setting the stage carefully is critical (8-342): We identified 3 key factors that were integrated into AWE from the beginning: clear goals, clear partner selection criteria, and performance monitoring. As noted above, the challenges in creating effective cross-institutional collaborations are inherent.

\section{Challenge 1:}

Normally the product of an idea by the PIs, a funded collaboration means that the coalition partners have to not only understand and agree to achievement of the project objectives, they need to develop active ownership of the project for it to succeed.

\section{AWE Experience:}

We began with concrete operational plans on how to communicate with the partners, based primarily on annual meetings and email. It soon became clear that the plan was not adequate to either convey the objectives of the project or to engage ownership. We added regular conference calls through which the directors presented information on how assessment implementation was going at their institution, share views on the value (or non value) of the products and processes being developed, and ask questions.

Electronic media were invaluable in achieving full participation and ownership of the project and have great potential to lubricate geographically scattered collaborations. (9) Easy and consistent access to all AWE materials in whatever stage of development meant that all partners could find

"Proceedings of the 2005 American Society for Engineering Education and Annual Conference \& Exposition" Copyright, American Society for Engineering Education 
documents at any time, and comment on them. Since the project relied on content expert reviews from the partners, it was critical that we got their feedback in a timely and relevant way. As important, documenting that response had to be easy for the partners to perform. Early on we established an internal website where documents were stored along with webforms for comments and assessment of instruments and other AWE products.

The secure website also held progress spreadsheets on all of the survey and supporting instruments as well as individual and project to do lists and deadlines. The deadlines were reinforced by regular reminders of when items were due. The latter, performance monitoring, is a key success ingredient for effective collaborations. (8-342).

\section{Challenge 2:}

A primary value of cross-institutional collaborations is that they are diverse, which means that success relies on not only overcoming distance, but individual and institutional style differences and, most important, differing experience and knowledge levels.

\section{AWE Experience:}

Full disclosure is critical in bringing together a diverse group. The participants were selected on the basis of size of institutions, diversity of student populations, size and maturity of the WIE Program or initiative, and experience of the directors. We made sure that each participant knew why they were selected and why what they brought to the coalition was valuable for a successful outcome. Beyond that, regular communication is a key tool for continuing to address this and, in fact, all challenges.

A major lesson learned for the PIs was to not get caught up in the demands of deliverables, but to listen and clarify on a regular basis. Often the apparent obstacles arising from misunderstanding of directions or intent or even non-responsiveness, led us all to a better understanding of what was needed to create better products and outcomes. Integrating expert assessment knowledge with content experts led to a creative process in which we could develop better and different assessment tools. (11) As noted by Katz, et. al. (10), "collaboration may bring about a clash of views, a cross-fertilisation (sic) of ideas which may in turn generate new insights or perspectives that individuals, working on their own, would not have grasped (or grasped as quickly). The act of collaborating may thus be a source of stimulation and creativity." Likewise, Radcliffe (14), after looking at NSF engineering education coalitions to determine what lessons could be drawn for use in Australia, writes: "We need to draw together sometimes disparate initiatives in engineering education ... a around unifying themes if we are to effect the sort of cultural and institutional change that is called for to meet the current and future challenges facing engineering education."

Finally, through careful documentation and investigation into how partners were using (or not using) the instruments we discovered the need to create capacity building tools for future users.

\section{Challenge 3:}

An additional value is dissemination, but information sharing is only a first step; ways must be found to create in depth sharing and sustaining of information flow and subsequent idea generation.

"Proceedings of the 2005 American Society for Engineering Education and Annual Conference \& Exposition" Copyright, American Society for Engineering Education 
AWE Experience:

Effective dissemination among the partners is a necessary precursor to dissemination beyond the collaboration. All of the methods devised and outlined in challenge 1 above were critical to creating a sharing of knowledge that went beyond sharing information. The process of identifying each partner's knowledge base, drawing on individual expert experience and sharing ideas led to creating and transferring new knowledge. Important additional steps in developing dissemination of ideas and experience, along with information, were the presentation of papers on the AWE Project at national conferences. $(12,15,16)$. The PIs have also worked with partners to present workshops at national conferences.

\section{Challenge 4:}

Collaborators have to deal constantly with the pull of day-to-day demands of the job.

\section{AWE Experience:}

There has to be obvious benefit for collaborators to maintain active participation. Developing relevant and usable materials provides basic motivation, but beyond that an effective collation becomes an "Intellectual companionship" that has "the effect of "plugging' the researcher into a wider network of contacts in the scientific community." (10) The process of implementation coupled with the opportunity to continuously critique and improve methods, developing products and understanding created a mutually satisfying knowledge-based community of peers.

Support from the top is also critical and carries with it the opportunity for increased visibility within one's own institution. AWE partners reported that participation in the project increased their integration into their home institutions and helped them create extended and functional networks. "I worked very closely, due to this grant, with many departments on campus, especially the office of Institutional Research and planning and collected lots of data I did not know exist," reported one. Another writes that, "Our grant has made me cognizant of [we] could and should be working collaboratively to recruit and retain students. We're in the process of scheduling a meeting across departments to begin collecting data on all institutional K-12 pipeline programs and how we can track our joint efforts to recruit students." Partners also reported gain in national visibility because of the grant and, significantly, anticipation of the roll out of AWE products: "[I've gained] Recognition from others that we are part of the grant and working on this 'great project'. Others can't wait for the products to be available. I've heard from people from our Women in Natural Sciences Program at UT, GirlStart, SWE, etc.” (2)

\section{Challenge 5:}

Collaborations are expensive and generally rely on outside funding: Sustaining the effort once the funding is gone remains the largest challenge.

\section{AWE Experience:}

The process of constant feedback from AWE partner directors helped us to create assessment instruments and other products that they report they will continue to use beyond the scope of the grant. In addition, the visibility reported above helped some directors in gaining additional resources to continue the assessment initiatives at their institution: "This grant helped me make a case for hiring a new person to help with the data collection and analysis in the future." Most also reported making changes in their operating and planning procedures that integrated AWE materials into their programming. "We have refined/defined objectives for our various programs and initiatives to make them measurable, etc.," writes one. "We're really getting interesting

"Proceedings of the 2005 American Society for Engineering Education and Annual Conference \& Exposition" Copyright, American Society for Engineering Education 
results on some of our programs and it is helping us figure out what we want to continue, change or discontinue," reported another. (2)

\section{Conclusion}

The overall benefits of collaborations and coalitions are great and as seen by the results from our director participants more than balance out the costs and investments if the collaboration is carefully managed with ample opportunity for communication, active input into development of outcomes, and tools for participation and accountability. While the start up costs can be high, there is a lasting competitive advantage of bringing together representatives of institutions to more efficiently identify problems and create solutions. The seven partner institutions all gained strategically (by using shared knowledge and experience to create universally usable assessment and support instruments); in knowledge sharing and creation (bringing together a diverse set of experiences and expertise created usable and relevant assessment instruments and uncovered the need for career development tools); and politically, gaining greater visibility in home institutions and beyond and creating functional and extended professional networks. The authors of course recognize that it remains to be seen whether the changes in the way the director participants do their jobs are so well integrated that they will remain post funding. Our plans for dissemination and institutionalization include ongoing support systems that will enable both the initial director participants as well as new ones to adopt and effectively use the AWE assessment tools, and to collaborate with each other based on their results.

\section{Bibliography}

1. Bogue, B., \& Marra, R. (2001). Informal Survey of WIE Directors. University Park, PA: Penn State University.

2. Bogue, B., \& Marra, R. (2001-03). Reflections: Annual Surveys of AWE Partners. University Park, PA: Penn State University.

3. Brawner, Catherine, Robert C. Serow. "Growing Pains: An Evaluation of the SUCCEED Coalition."

4. Carpinelli, John D. and Angelo Perna. "Engineering Education Coalitions: Perspective from a Partner University." International Conference on Engineering Education, August 2001, Oslo Norway. 6E2-12-14

5. Coward, H. Roberts, Catherine P. Ailes, and Roland Bardon. 2000. Progress of the Engineering Education Coalitions (NSF 00-116). Final Report. Engineering Education and Centers Division, National Science Foundation, Arlington, VA.

6. Ebrahim, Alnoor. Institutional Preconditions to Collaboration: Indian Forest and Irrigation Policy in Historical Perspective. Administration \& Society.2004; 36: 208-242.

7. Frair, K. Froyd, J. Rogers, G. Watson, K. The NSF foundation coalition-past, present, and future. Frontiers in Education Conference Proceedings, 1996. FIE '96. 26th Annual Conference. 3 vol. Salt Lake City, UT. $\mathrm{xl}+1517$

8. Hardy, Cynthia, Nelson Phillips and Thomas B. Lawrence. "Resources, Knowledge and Influence: The Organizational Effects of Interorganizational Collaboration." Journal of Management Studies 40:2. March 2003. 321-347.

9. Horgan, Barbara. Cooperation and Competition: Case Studies of Academic Partnerships Using Information Technology. Case Studies, March 1998.

10. Katz, J. Sylvan, Ben R. Martin. What is Research Collaboration? Research Policy 26 (1997( 1-18)

11. Marra, R., Bogue, B. (2004). "The Assessing Women in Engineering (AWE) Project: A Model for Sustainable and Profitable Collaboration". Journal of Women and Minorities in Science and Engineering, $\underline{10}(3), 283-295$.

12. Marra, R.M. and Bogue, B. (2003). "A.W.E. (Assessing Women in Engineering) - Designing Tools for Success Using Collaboration". D. Budny, G. Bjedov (Eds.) 33rd ASEE/IEEE Frontiers in Education Conference (FIE) 2003, Boulder, CO. (CD and website). available online at fie.engrng.pitt.edu/fie2003/.

13. National Science Foundation Engineering Directorate Webpage, http://www.nsf.gov/od/lpa/news/publicat/nsf04009/eng/eec.htm. Accessed January 5, 2005.

"Proceedings of the 2005 American Society for Engineering Education and Annual Conference \& Exposition" Copyright, American Society for Engineering Education 
14. Radcliffe, David. "The Lessons We Learn: Reflections on an NSF Engineering Education Coalition," Australasian J. of Engng. Educ., Vol. 6, No. 2

15. Ruel, B., Berry, T., Bogue, B., Hart, B., Marra, R., Reyes, M., (2002) WIE Program Assessment Tools: How They Will Benefit Your Programs, Your Students, Your Institution, and WIE Programs Nationally," Women Engineering Program and Advocates Network (WEPAN) National Conference, Detroit, MI.

16. Ruel, B., Bogue, B., Reyes, M., Hart, B. (2004) "Developing Peer Mentor Programs That Build Community and Increase Retention.” Women Engineering Program and Advocates Network (WEPAN) National Conference, Albuquerque, NM.

17. Shafer, B.S. \& Reed, W.S. (July, 1996). Consortia in higher education. NACUBO Business Officer, 30(1), 51-52.

\section{Biographical Information}

BARBARA BOGUE is Associate Professor of Engineering Science and Mechanics and Women in Engineering. She is co-PI of the NSF-funded Assessing Women in Engineering Project and of Facultyforthefuture.org. Her research interests include recruitment and retention of women in engineering, assessment and career development.

ROSE M. MARRA is an Assistant Professor in the School of information science and Learning Technologies at the University of Missouri. She is PI of the NSF-funded Assessing Women in Engineering Project. Her research interests include gender equity issues, the epistemological development of college students, and promoting meaningful learning in web-based environments. 